\title{
Kernos
}

Revue internationale et pluridisciplinaire de religion grecque antique

$29 \mid 2016$

Varia

\section{La Religion grecque}

\section{Pierre Brulé}

\section{(2) OpenEdition \\ Journals}

\section{Édition électronique}

URL : http://journals.openedition.org/kernos/2417

DOI : 10.4000/kernos.2417

ISSN : 2034-7871

\section{Éditeur}

Centre international d'étude de la religion grecque antique

\section{Édition imprimée}

Date de publication : 1 octobre 2016

Pagination : 423-424

ISSN : 0776-3824

Référence électronique

Pierre Brulé, « La Religion grecque », Kernos [En ligne], 29 | 2016, mis en ligne le 01 octobre 2016, consulté le 17 novembre 2020. URL : http://journals.openedition.org/kernos/2417 ; DOI : https:// doi.org/10.4000/kernos.2417

Ce document a été généré automatiquement le 17 novembre 2020.

Kernos 


\title{
La Religion grecque
}

\author{
Pierre Brulé
}

\section{RÉFÉRENCE}

Jan N. BREMMER, La Religion grecque, traduit de l'anglais par A. Hasnaoui, Paris, Les Belles Lettres, 2012. 1 vol. 13,5 × 21 cm, 228 p. ISBN : 978-2-251-44445-1.

1 Au début des années 2000, un tel ouvrage manquait cruellement aux étudiants qui découvraient la religion grecque. Pourtant, les francophones n'avaient pas trop à se plaindre : dans des perspectives différentes et heureusement complémentaires, je leur recommandais ceux de Louise Bruit et Pauline Schmitt-Pantel (1989'1), de Madeleine Jost $\left(1992^{2}\right)$, de Vinciane Pirenne-Delforge $\left(1999^{3}\right)$ de sorte qu'ils parviennent, dans un second temps, à une lecture, le crayon à la main, de la synthèse de Louis Gernet $\left(1932^{4}\right.$ !). Mais, surtout après la catastrophique semestrialisation, à des étudiants qui, très majoritairement, rechignaient à lire les langues étrangères, on pouvait difficilement leur demander plus, et, comme l'étude locale de R.Parker (19965), la Greek Religion (1985) issue de la Griechische Religion (1977) de Walter Burkert, ne pouvait raisonnablement leur servir que d'appui pour des sujets précis ${ }^{6}$. Comme j'ai envié les collègues allemands et britanniques. Et ne parlons pas du temps où les Bruit-SchmittPantel, Jost, Pirenne, n'existaient pas. Ne sommes-nous pas allés, avec Pierre Lévêque jusqu'à évoquer l'opportunité d'une traduction de M.P. Nilsson (1941) (avec état des questions et bibliographie mise à jour)!

2 Et voici donc maintenant en main, mise en français et très utilement complétée, une Greek Religion âgée de vingt-deux ans déjà et que des dizaines de recenseurs ont déjà commentée, qu'ils ont louée avec raison, chacun y épinglant néanmoins tels défauts ou soi-disant défauts, alors que, d'enthousiasme, le chœur des amateurs satisfaits en a déjà chanté les louanges aux quatre vents. Il n'est peut-être donc pas nécessaire de répéter ici ce que tout le monde sait: que c'est aujourd'hui encore le meilleur appui que le public informé et celui qu'on appelle le public «averti » puissent trouver. Il y trouve, dans une présentation claire et un abord aisé, à la fois une information sûre et toutes 
sortes de suggestions à réflexions et à débats. C'est donc sur d'autres plans que je voudrais profiter de cette nouvelle édition pour introduire deux courtes remarques générales.

3 Le livre compte 228 pages. Et encore, bien des pages sont occupées par les notes; des notes qui sont importantes dans le projet de l'A. ; là, en effet, se découvre par addition une véritable bibliographie du sujet (absente ailleurs dans le livre, comme c'était le cas dans celui de W. Burkert), une mise à jour par l'A. jusqu'en 2011, et puis préfaces et index. De « vrai » texte, donc, 130 environ, seulement. C'est court, c'est un tout petit peu plus que la taille des classiques Que sais-je? français. Toutefois, cette brièveté étonnera peu l'observateur de la production de telles synthèses sur le temps long: quand il mesure l'évolution du poids des ouvrages sur la religion grecque depuis une centaine d'années, depuis les plus ambitieuses synthèses. Effet d'une diététique ? Quel amaigrissement que de passer de M.P. Nilsson à W. Burkert, puis une nouvelle cure de Burkert, à Bruit-Schmitt et enfin à J. Bremmer. Ceci, avec des évolutions quantitativement divergentes : de moins en moins de détails, de plus en plus de survol, de moins en moins de diversité géographique (ah! le poids irrépressible d'Athènes!), mais de plus en plus de réflexions sur les concepts et sur les méthodes des historiens. Cette évolution n'est pas que quantitative, elle apparaît concomitante d'approches méthodologiques nouvelles. Elle trouve, peut-être et en partie, son explication dans un fait qui étonnera que les non-spécialistes : la masse documentaire sur laquelle devrait se fonder aujourd'hui une synthèse aussi ambitieuse que le furent celles de M.P. Nilsson et même de W. Burkert a crû de manière importante (et avec une ampleur inattendue) : presque chaque année nous avons vu paraître des documents nouveaux, essentiellement, mais pas seulement épigraphiques, qui ont renouvelé et complété, parfois modifié nos connaissances, nos points de vue, qui obligent même à rependre des questions fondamentales et qu'on pouvait croire fermées (ainsi à propos des rites de purification). C'est donc à la fois à des lumières nouvelles sur la religion de régions périphériques dans des périodes souvent délaissées, c'est aussi à élaborer de nouvelles synthèses tenant compte de ces apports documentaires et par des nouvelles réflexions que les auteurs de futures synthèses de grande ampleur devraient s'attaquer.

4 La seconde remarque sera plus brève. Ce qui est aussi très significatif de l'évolution de l'historiographie, c'est que cette Religion grecque est, comme les précédentes depuis W. Burkert, une "religion grecque ", alors que leurs ancêtres se disaient Histoire de la religion grecque. Cette Religion grecque choisit sa période, c'est l'archaïque et la classique, comme d'habitude, et s'y tient à l'exception de deux perspectives plus historisantes : le chapitre VII : «Les Transformations » et un court appendice : « La genèse de la religion grecque ». Le chapitre VII traite des mystères d'Éleusis - l'hypothèse de la transformation de rites initiatiques de puberté masculine en programme héortologique de la cité va seule dans le sens d'une réelle perspective historique -, puis on passe aux idées orphiques et aux mystères dionysiaques pour finir par les changements structurels de la religion et conclure rapidement sur la « mutation de la fin de l'époque classique ». Alors, c'est le moment de plaider pour que cette façon de découper l'histoire religieuse soit abandonnée quand tant de documents d'époques ultérieures sont utilisés sans vergogne pour écrire l'histoire de l'époque classique, que tant de documents importants pour la compréhension de la pensée religieuse grecque n'obéissent pas au découpage historique traditionnel (politique). 


\section{NOTES}

1. .La Religion grecque, Paris, Armand Colin.

2. .Aspects de la vie religieuse en Grèce. Du début du ve siècle à la fin du III siècle av. J.-C., Paris, Sedes.

3. . « Religion grecque », in Y. LEHMANN (dir.), Religions de l'Antiquité, Paris, PUF, p. 79-175.

4. .En collaboration avec A. BOULANGER, Le Génie grec dans la religion, Paris, Albin Michel, rééd. 1970.

5. .Athenian Religion. A History, Oxford, OUP, à laquelle viendra s'ajouter Polytheism and Society at Athens, en 2005, toujours à Oxford.

6. .La somme de Burkert est aujourd'hui disponible en français grâce à la traduction de Pierre Bonnechere, assortie d'une mise à jour bibliographique bienvenue (La Religion grecque à l'époque archaïque et classique, Paris, Picard, 2011).

7. .Geschichte der griechischen Religion, 1-2. München 1941 (2 $2^{e}$ éd. 1955). 1. Bis zur griechischen Weltherrschaft, 823 p. ; 2. Die hellenistische und römische Zeit, 714 p. (2 ${ }^{\mathrm{e}}$ éd. 1961).

8. .Le public anglophone, quant à lui, dispose désormais de l'excellent On Greek Religion de Robert Parker (2011).

\section{AUTEURS}

\section{PIERRE BRULÉ}

Université de Rennes 2 